Check for updates

Cite this: RSC Adv., 2018, 8, 24857

Received 3rd May 2018

Accepted 27th June 2018

DOI: $10.1039 / \mathrm{c} 8 \mathrm{ra03806f}$

rsc.li/rsc-advances

\section{Production of ethylene glycol from direct catalytic conversion of cellulose over a binary catalyst of metal-loaded modified SBA-15 and phosphotungstic acid}

\begin{abstract}
Shitao Yu, ${ }^{a}$ Xincheng Cao, (D) a Shiwei Liu, ${ }^{\star a}{ }^{2 u} L^{a}$ and Qiong Wu ${ }^{\text {ab }}$
This study presents the utilization of a binary catalyst composed of metal-loaded modified SBA-15 (M/SBA-15) and phosphotungstic acid $\left(\mathrm{H}_{3} \mathrm{PW}_{12} \mathrm{O}_{40}\right)$ for ethylene glycol (EG) production from direct catalytic conversion of cellulose. M/SBA-15 ( $M=\mathrm{Ru}, \mathrm{Au}, \mathrm{Pd}, \mathrm{Pt}, \mathrm{Rh}$ and $\mathrm{Ni}$ ) catalysts were prepared using the impregnation method and characterized by means of XRD, $\mathrm{N}_{2}$ physisorption, TEM and $\mathrm{H}_{2}$-temperature-programmed reduction $\left(\mathrm{H}_{2}{ }^{-}\right.$ TPR) techniques. Their catalytic performance was then studied in detail on the basis of cellulose conversion and the selectivity of polyols and EG. The results showed that the mesoporous structure of the SBA-15 sample was well maintained after the metal-loaded modification, and almost all of the selected catalysts gave about $100 \%$ conversion of cellulose. However, the selectivity for EG was greatly different. Among the various binary catalysts, the combination of $\mathrm{Rh} / \mathrm{SBA}-15$ and $\mathrm{H}_{3} \mathrm{PW}_{12} \mathrm{O}_{40}$ gave the best selectivity to EG (55.5\%), whereas the worst selectivity of EG (11\%) was obtained over the Au/SBA-15 and $\mathrm{H}_{3} \mathrm{PW}_{12} \mathrm{O}_{40}$ system under identical conditions. In addition to phosphotungstic acid, other $W$ compounds were also studied in combination with the Ru/SBA-15 catalyst. The results showed that the EG selectivity depended on the W compounds as follows: $\mathrm{H}_{4} \mathrm{SiW}_{12} \mathrm{O}_{40}<\mathrm{H}_{2} \mathrm{WO}_{4}<\mathrm{H}_{3} \mathrm{PW}_{12} \mathrm{O}_{40}$. Therefore, the binary catalyst of Rh/SBA-15 and $\mathrm{H}_{3} \mathrm{PW}_{12} \mathrm{O}_{40}$ showed the greatest potential for $\mathrm{EG}$ production from direct catalytic conversion of cellulose.
\end{abstract}

\section{Introduction}

The excessive consumption of fossil fuel and the ever-increasing emissions associated with their consumption have spurred a great deal of research for alternative energy sources. ${ }^{1}$ Biomass as a clean and renewable carbon source on earth has received increasing attention. ${ }^{2}$ With regards to the utilization of biomass, the conversion of cellulose holds great potential due to its nonedible nature and huge availability. ${ }^{3}$ Nevertheless, cellulose, as a biopolymer bonded by $\beta-1,4$-glucosidic bonds, contains abundant hydrogen bonds; hence, it is difficult to convert it by solvents or catalysts under mild conditions. ${ }^{4}$ Therefore, the robust structure of cellulose remains a great concern for its efficient transformation under mild conditions.

In order to achieve high energy efficiency and atom economy in the conversion of cellulose, different primary routes have been explored. ${ }^{5-8}$ One of the most promising routes is direct catalytic conversion of cellulose to polyols, for which the polyol products can be directly used as chemicals or precursors to produce renewable chemicals. ${ }^{9}$ This process couples the $\mathrm{C}-\mathrm{C}$ breaking

${ }^{a}$ College of Chemical Engineering, Qingdao University of Science and Technology, Qingdao 266042, China. E-mail: liushiweiqust@126.com; Fax: +86 532 84022719; Tel: +8653284022719

${ }^{b}$ Department of Chemical \& Biomolecular Engineering, University of Tennessee Knoxville, 419 Dougherty Engineering Bldg., Knoxville, Tennessee 37996, USA reaction of cellulose by an acid catalyst to form glucose and the hydrogenation of the glucose over the metal catalysts to generate the polyols. ${ }^{7}$ Amongst the polyol products, EG has a large market and is widely used in the pharmaceutical, cosmetic, food, dye, plastic and automobile industries; thus, it is considered to be a high-value market product. ${ }^{10}$ Currently, the manufacture of EG is mainly dependent on petroleum resources using the method of oxidation, followed by hydration of ethylene. ${ }^{\mathbf{1 1}}$ Therefore, obtaining EG from the direct transformation of cellulose is very significant because of its possible environment benefits and the current concern over the depletion of fossil fuel sources. For this catalytic approach, catalyst plays an important role in the selectivity of a specific polyol product. For example, using Ru/AC as the catalyst ( $\mathrm{AC}=$ activated carbon), Liu et al. obtained $\sim 40 \%$ yield of hexitols. ${ }^{12}$ Zhang et al. obtained EG yield of up to $\sim 54 \%$ using $\mathrm{H}_{2} \mathrm{WO}_{4}$ in combination with $1.2 \% \mathrm{Ru} / \mathrm{AC}$ catalyst. ${ }^{13}$

It is well known that the dispersion and accessibility of active sites have a significant impact on the activity and selectivity of the catalyst. To develop efficient catalysts, extensive studies have been conducted by using different technologies. For example, Zhang et al. used the traditional active carbon (AC) as support for dispersing Ni particles to improve the activity of the catalyst in the catalytic conversion of cellulose to EG. ${ }^{14}$ Although the AC had large surface area, the active sites exhibited low dispersion and poor accessibility 
due to the microporous structure of AC. Additionally, the microporous carbon used as support may have a negative effect on the overall catalytic performance due to its steric hindrance and diffusion limitations. For this reason, mesoporous carbon (CMK-3) with $\mathrm{WC}_{x}$ active sites was synthesized to catalyze cellulose. ${ }^{15}$ The $\mathrm{WC}_{x} / \mathrm{CMK}-3$ catalyst exhibited better catalytic performance than the $\mathrm{WC}_{x} / \mathrm{AC}$ catalyst due to its good accessibility and the dispersion of the active sites. However, the rigorous synthesis conditions and difficulty in replication greatly limited its application. In 2010, Zheng et al. developed a series of bimetallic catalysts for the conversion of cellulose, including $\mathrm{Ru}-\mathrm{W}, \mathrm{Ni}-\mathrm{W}, \mathrm{Ir}-\mathrm{W}$ and $\mathrm{Pt}-\mathrm{W}$ supported on different carriers. It was found that the maximum yield of EG $(75.4 \%)$ was obtained over the Ni-W/SBA-15 catalyst. $^{16}$ In this context, the mesoporous material SBA-15 can be used as the catalyst for catalytic cracking of cellulose due to its ordered hexagonal mesostructure and large pore size, which can facilitate the conversion of bulky molecules. ${ }^{17}$ However, the pure silica SBA-15 material had almost no catalytic activity because of the absence of active sites. ${ }^{18}$ Therefore, the catalyst must be further modified and improved to solve this problem. Among all the modification methods, the impregnation method has remarkable advantages such as simple preparation and easier industrial application. ${ }^{19} \mathrm{Up}$ to now, metals, including $\mathrm{Ni},{ }^{20} \mathrm{La},{ }^{21} \mathrm{Al},{ }^{22} \mathrm{Ca}^{23}$ and $\mathrm{Mg}^{24}$ modified with SBA-15 have shown good catalytic performance in the catalytic cracking of vegetable oils. It is worth mentioning that these catalysts were all prepared using the impregnation method. Nevertheless, there are few reports related to obtaining the desired products from catalytic conversion of cellulose over these catalysts.

In this study, we evaluated the catalytic performances of various binary catalysts of $\mathrm{M} / \mathrm{SBA}-15(\mathrm{M}=\mathrm{Ru}, \mathrm{Au}, \mathrm{Pd}, \mathrm{Pt}, \mathrm{Rh}$ and $\mathrm{Ni}$ ) mesoporous materials and different $\mathrm{W}$ compounds and chose the best binary catalyst to produce EG from the catalytic conversion of cellulose. To the best of our knowledge, there is no clear picture of the comparative performance of these catalysts. Therefore, it is expected that the results will provide the vital guidance for the rational selection of highly active binary catalysts for the catalytic conversion of cellulose to EG.

\section{Experimental}

\subsection{Materials}

Microcrystalline cellulose (MCC, average molecular weight: 90 000) was purchased from Sigma-Aldrich and used without further purification. Other materials, namely, tungstic acid $\left(\mathrm{H}_{2} \mathrm{WO}_{4}\right)$, phosphotungstic acid hydrate $\left(\mathrm{H}_{3} \mathrm{O}_{40} \mathrm{PW}_{12} \cdot x \mathrm{H}_{2} \mathrm{O}\right)$, tungstosilicic acid hydrate $\left(\mathrm{H}_{4}\left[\mathrm{Si}\left(\mathrm{W}_{3} \mathrm{O}_{10}\right)_{4}\right] \cdot x \mathrm{H}_{2} \mathrm{O}\right)$, ruthenium chloride trihydrate $\left(\mathrm{RuCl}_{3} \cdot 3 \mathrm{H}_{2} \mathrm{O}\right)$, rhodium chloride trihydrate $\left(\mathrm{RhCl}_{3} \cdot 3 \mathrm{H}_{2} \mathrm{O}\right)$, chloroplatinic acid hexahydrate $\left(\mathrm{H}_{2} \mathrm{PtCl}_{6} \cdot 6 \mathrm{H}_{2} \mathrm{O}\right)$, nickel chloride hexahydrate $\left(\mathrm{NiCl}_{2} \cdot 6 \mathrm{H}_{2} \mathrm{O}\right)$, palladium chloride $\left(\mathrm{PdCl}_{2}\right)$, chloroauric acid tetrahydrate $\left(\mathrm{HAuCl}_{4} \cdot 4 \mathrm{H}_{2} \mathrm{O}\right)$, triblock copolymer-P123 $\left(\mathrm{EO}_{20} \mathrm{PO}_{70^{-}}\right.$ $\mathrm{EO}_{20}$ ), and tetraethyl orthosilicate (TEOS), were all purchased from Aldrich and used after drying without any further treatment.

\subsection{Preparation and characterization of catalysts}

SBA-15 was synthesized by the hydrothermal method according to the literature. ${ }^{25}$ The molar composition of the mixture was 1TEOS : $0.02 \mathrm{P}_{123}: 6 \mathrm{HCl}: 192 \mathrm{H}_{2} \mathrm{O}$.

$\mathrm{Ru} / \mathrm{SBA}-15$ catalyst was prepared by the wet impregnation method. First, $1.0 \mathrm{~g}$ SBA-15 powder was immersed into $20 \mathrm{~mL}$ $\mathrm{RhCl}_{3} \cdot 3 \mathrm{H}_{2} \mathrm{O}$ solution (10 wt\%) under stirring at $80^{\circ} \mathrm{C}$. After evaporation at $80{ }^{\circ} \mathrm{C}$, the sample was dried at $100{ }^{\circ} \mathrm{C}$ for $12 \mathrm{~h}$ and then calcined at $550^{\circ} \mathrm{C}$ for $6 \mathrm{~h}$ in air. The solid obtained was reduced with $\mathrm{H}_{2}\left(20 \mathrm{~cm}^{3} \mathrm{~min}^{-1}\right)$ at $550{ }^{\circ} \mathrm{C}$ for $2 \mathrm{~h}$ at a heating rate of $2{ }^{\circ} \mathrm{C} \mathrm{min}{ }^{-1}$, giving the Ru-SBA-15 catalyst. Other catalysts such as $\mathrm{Ni}(\mathrm{Pt}, \mathrm{Pd}, \mathrm{Au}, \mathrm{Rh}) / \mathrm{SBA}-15$ were also prepared using the same method.

XRD patterns were recorded on a XB-3A instrument operating at $40 \mathrm{kV}$ and $100 \mathrm{~mA}$ with $\mathrm{Cu} \mathrm{K} \alpha$ radiation $(\lambda=0.15418$ $\mathrm{nm}$ ) in the $2 \theta$ range from $0.5^{\circ}$ to $10^{\circ}$. The experiment conditions were as follows: a step width of $0.01^{\circ}$ and scan speed of $2^{\circ} \min ^{-1}$. The BET specific surface area and pore size distribution of the catalysts were measured from $\mathrm{N}_{2}$ adsorption/ desorption isotherms at $-77 \mathrm{~K}$ using a Micromeritics ASAP 2000 system. TEM images were recorded to observe the dispersion degree of the metal phase. Transmission electron microscopy (TEM) was conducted on a JEOS-2020 F electron microscope operating at an accelerating voltage of $200 \mathrm{kV}$. The metal contents of the as-synthesized catalyst were measured by inductively coupled plasma-atomic emission spectrometry (ICP-AES) technique on a Varian VISTA-PRO AX spectrophotometer.

$\mathrm{H}_{2}$-temperature-programmed reduction $\left(\mathrm{H}_{2}\right.$-TPR) was performed in a fixed reactor. Prior to the TPR, $100 \mathrm{mg}$ samples were purged in Ar at $100{ }^{\circ} \mathrm{C}$ for $1 \mathrm{~h}$. Subsequently, the samples were heated in a flow of pure $\mathrm{H}_{2}$ from $100{ }^{\circ} \mathrm{C}$ to $800{ }^{\circ} \mathrm{C}$ at a rate of $10{ }^{\circ} \mathrm{C} \min ^{-1}$ and were analyzed by a Hiden QIC-20 mass spectrometer.

\subsection{Catalytic cracking cellulose}

The catalytic conversion of cellulose was carried out in a Teflon-lined stainless autoclave $(100 \mathrm{~mL})$ at $245{ }^{\circ} \mathrm{C}$ for $4 \mathrm{~h}$ under 5.0 MPa hydrogen pressure. Typically, the reaction mixture was composed of cellulose $\left(\mathrm{W}_{1}\right)$, binary catalyst $(0.1 \mathrm{~g}$ M/SBA-15 and $0.02 \mathrm{~g} \mathrm{~W}$ compounds) and $25 \mathrm{~mL}$ of $\mathrm{H}_{2} \mathrm{O}$, which were successively placed in the autoclave. Then, the reactor was purged with nitrogen at about $0.2 \mathrm{MPa}$ to completely remove the air. The reactor was heated by external electrical resistance at a heating rate of $15{ }^{\circ} \mathrm{C} \min ^{-1}$ and its temperature was measured using a calibrated thermocouple. After the reaction, the cellulose $\left(\mathrm{W}_{2}\right)$ remaining in the reactor was collected by centrifugation and used to calculate the cellulose conversion. The compositions of liquid-phase products were analyzed by HPLC equipped with RID (Refractive Index Detector). The separation was realized on a column of Bio-Rad HPX-87X column $(8 \times 300 \mathrm{~mm})$ with $0.05 \mathrm{M} \mathrm{H}_{2} \mathrm{SO}_{4}$ aqueous solution as mobile phase, and each product $\left(\mathrm{W}_{\mathrm{i}}\right)$ was quantified using the external standard method. The conversion (wt $\%$ ) of cellulose and selectivity of the desired product (wt\%) 
were calculated as follows:

$$
\begin{aligned}
& \text { Conversion }(\%)=\frac{\mathrm{W}_{1}-\mathrm{W}_{2}}{\mathrm{~W}_{1}} \times 100 \% \\
& \text { Selectivity }(\%)=\frac{\mathrm{W}_{\mathrm{i}}}{\mathrm{W}_{1}-\mathrm{W}_{2}} \times 100 \%
\end{aligned}
$$

\section{Results and discussion}

\subsection{Catalyst characterization}

The XRD patterns of the pure silica SBA-15 and M/SBA-15 samples are shown in Fig. 1. Three characteristic reflection peaks of the SBA- 15 are present at $2 \theta$ of $0.9^{\circ}, 1.6^{\circ}$ and $1.8^{\circ}$, which were indexed as (100), (110) and (200) diffraction peaks, respectively. The XRD profiles matched well with the hexagonally-structured SBA-15 sample reported by Zhao et al. ${ }^{25}$ Almost all of the patterns of the M/SBA-15 samples showed the three peaks with high intensity, indicating that the hexagonal mesostructure of the SBA-15 was well maintained even after the metal species were introduced.

Fig. 2 displays the $\mathrm{N}_{2}$ adsorption-desorption and corresponding pore size distribution isotherms of the SBA-15 and M/ SBA-15 samples. It can be seen from Fig. 2(a) that all of the samples exhibit type IV isotherms with an H1 type hysteresis loop, which is a characteristic of mesoporous materials. ${ }^{26}$ This indicates that the pure silica SBA-15 and all M/SBA-15 samples had an ordered mesostructure. The textural parameters of different samples are summarized in Table 1. It was found that the SBA-15 material had high specific surface area $\left(580 \mathrm{~m}^{2} \mathrm{~g}^{-1}\right)$, but the surface areas of the M/SBA-15 samples were reduced within the range of $394-482 \mathrm{~m}^{2} \mathrm{~g}^{-1}$. Moreover, the M/SBA-15 samples exhibited smaller total pore volume and larger average pore size compared to those of the pure silica SBA-15

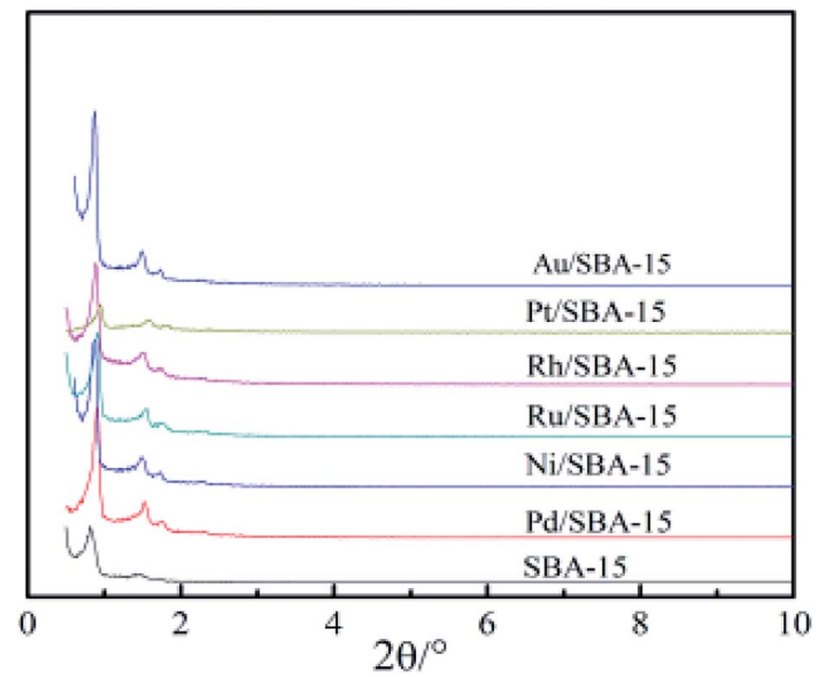

Fig. 1 XRD patterns of the SBA-15 and M/SBA-15 samples. sample. This may be due to the accumulation of metal species on the surface of the mesoporous material or deep into the channel interior, thus hindering the interior channel of the mesoporous material SBA-15 and resulting in smaller pore volume. Moreover, the metal species loaded on SBA-15 will partially block most of the micropores in the M/SBA-15 samples, thereby increasing the average pore size. All these results indicated that the metal phases were dispersed on the surface of the SBA-15 support. According to Table 1, the specific surface areas and total pore volumes of the $\mathrm{Pd}(\mathrm{Ni}, \mathrm{Pt}) / \mathrm{SBA}-15$ samples were relatively low compared to those of the other samples, which may be due to the accumulation of excess metal species on the surface of the SBA-15 support.

The particle size distributions of the metal phase on the surface of the SBA- 15 support were determined by TEM images. As shown in Fig. 3, the average particle size of different catalyst was different. The average particle sizes of $\mathrm{Rh}$ and $\mathrm{Ru}$ on the SBA-15 support were $5.78 \mathrm{~nm}$ and $4.25 \mathrm{~nm}$, respectively (Fig. 3(c and d)). However, the average particle sizes of Ni/SBA-15 and Pd/ SBA-15 were larger than $20 \mathrm{~nm}$ (Fig. 3(e and f)), which may be due to the aggregation of metal species on the surface of SBA15. ${ }^{27}$ These results showed that the metal particles $\mathrm{Au}, \mathrm{Ru}$ and Rh have good dispersibility on the SBA-15 support, which is consistent with the structural parameters of the different samples obtained from the $\mathrm{N}_{2}$ adsorption-desorption experiment.

Fig. 4 displays the $\mathrm{H}_{2}$-TPR profiles of the SBA-15 and the M/ SBA-15 samples. As can be seen from Fig. 4, different M/SBA-15 catalysts showed the hydrogen desorption peaks at different temperatures. This indicates that the metal species were successfully loaded on the SBA-15 sample and had catalytic hydrogenation capability. It is worth noting that the $\mathrm{Ni}(\mathrm{Pd}) /$ SBA-15 samples showed higher hydrogen desorption peaks compared to those observed for the other catalysts, which may be due to the accumulation of excess $\mathrm{Ni}$ and Pd metal species on the surface of the SBA-15 support, which can be confirmed by the TEM images.

\subsection{Catalytic performance of the M-SBA-15 and $\mathrm{H}_{3} \mathrm{PW}_{12} \mathrm{O}_{40}$ binary system}

The catalytic performances of the various binary catalysts composed of M/SBA-15 and $\mathrm{H}_{3} \mathrm{PW}_{12} \mathrm{O}_{40}$ (TPA) were investigated in the catalytic conversion of cellulose. Table 2 shows the distribution of the main products, namely, ethylene glycol (EG), sorbitol (SO), mannitol (MA), 1,2-propylene glycol (PG), and glycerol (GY), obtained using different tested binary catalysts. As can be seen from Table 2, cellulose was almost totally converted even in the absence of M/SBA-15 catalysts (Entry 1), indicating that TPA plays a key role in the cracking cellulose reaction.

The EG selectivity significantly improved when the M/SBA-15 catalysts were introduced (Entries 3-8). According to the literature ${ }^{27}$ metal catalyst as a hydrogenation active centre has a synergistic effect with the $\mathrm{W}$ compound, that is, the cellulose is hydrolyzed by $\mathrm{W}$ compound, followed by the metal-catalyzed hydrogenation of the formed intermediate products to obtain 

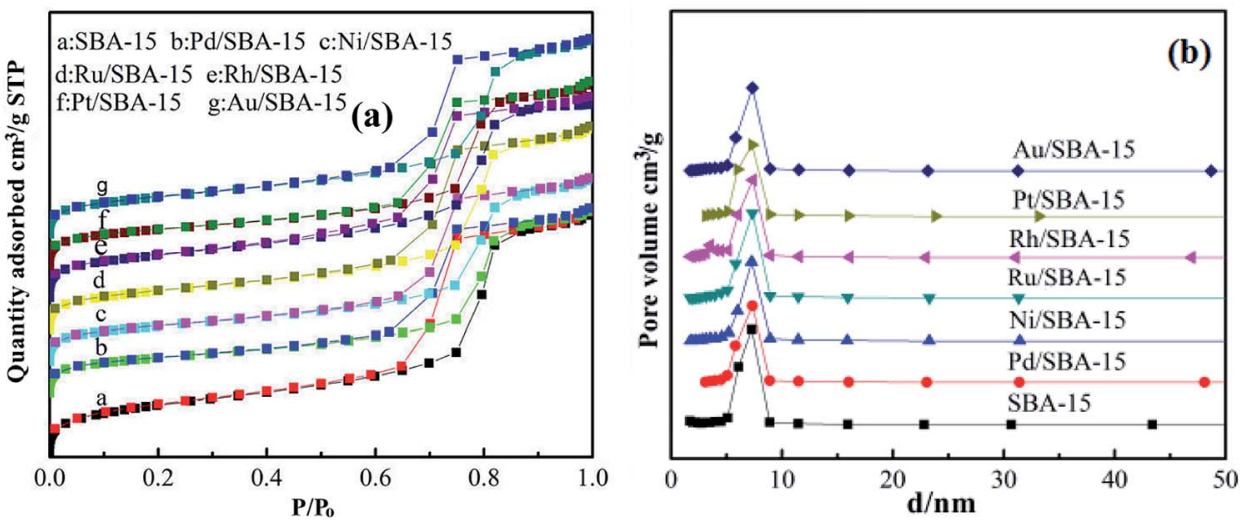

Fig. 2 (a) $\mathrm{N}_{2}$ adsorption-desorption isotherms and (b) BJH pore size distribution of SBA-15 and M/SBA-15 samples.

Table 1 Textural properties of SBA-15 and M/SBA-15 samples

\begin{tabular}{llllllll}
\hline Entry & Catalyst & $S_{\text {BET }}{ }^{a}\left(\mathrm{~m}^{2} \mathrm{~g}^{-1}\right)$ & $D_{\text {poresize }}{ }^{b}(\mathrm{~nm})$ & $V_{\text {total }^{c}}\left(\mathrm{~cm}^{3} \mathrm{~g}^{-1}\right)$ & $V_{\text {micro }}{ }^{d}\left(\mathrm{~cm}^{3} \mathrm{~g}^{-1}\right)$ & $V_{\text {meso }}{ }^{e}\left(\mathrm{~cm}^{3} \mathrm{~g}^{-1}\right)$ & Metal content $^{f}\left(\mathrm{wt}^{2}\right)$ \\
\hline 1 & SBA-15 & 580 & 7.25 & 1.15 & 0.01 & 1.14 & - \\
2 & Au/SBA-15 & 422 & 7.32 & 0.94 & 0.01 & 0.93 & 9.3 \\
3 & Pt/SBA-15 & 409 & 7.30 & 0.89 & 0.02 & 0.87 & 9.5 \\
4 & Rh/SBA-15 & 482 & 7.36 & 0.97 & 0.02 & 0.97 & 9.8 \\
5 & Ru/SBA-15 & 436 & 7.33 & 0.98 & 0.01 & 0.87 & 9.8 \\
6 & Ni/SBA-15 & 398 & 7.26 & 0.88 & 0.01 & 0.88 & 9.7
\end{tabular}

${ }^{a}$ From $\mathrm{N}_{2}$ absorption measurement (BET method). ${ }^{b}$ Average pore diameter calculated by BJH methods. ${ }^{c}$ Total pore volumes were obtained at $P / P_{0}$ $=0.99 .{ }^{d}$ Micropore volume was calculated using the $t$-plot method. ${ }^{e}$ Mesopore volume calculated as $V_{\text {Meso }}=V_{\text {Total }}-V_{\text {Micro }}{ }^{f}$ Metal content was measured from ICP-AES measurements.

the EG product. Scheme 1 depicts the possible reaction routes involved in cellulose conversion to polyols. The main reaction route for the EG formation involves (R1) hydrolysis of cellulose to glucose, (R2) retro-aldol condensation of glucose to form glycolaldehyde (GA), and (R3) the hydrogenation of GA to form EG. ${ }^{28}$ Such a reaction route indicates the importance of the
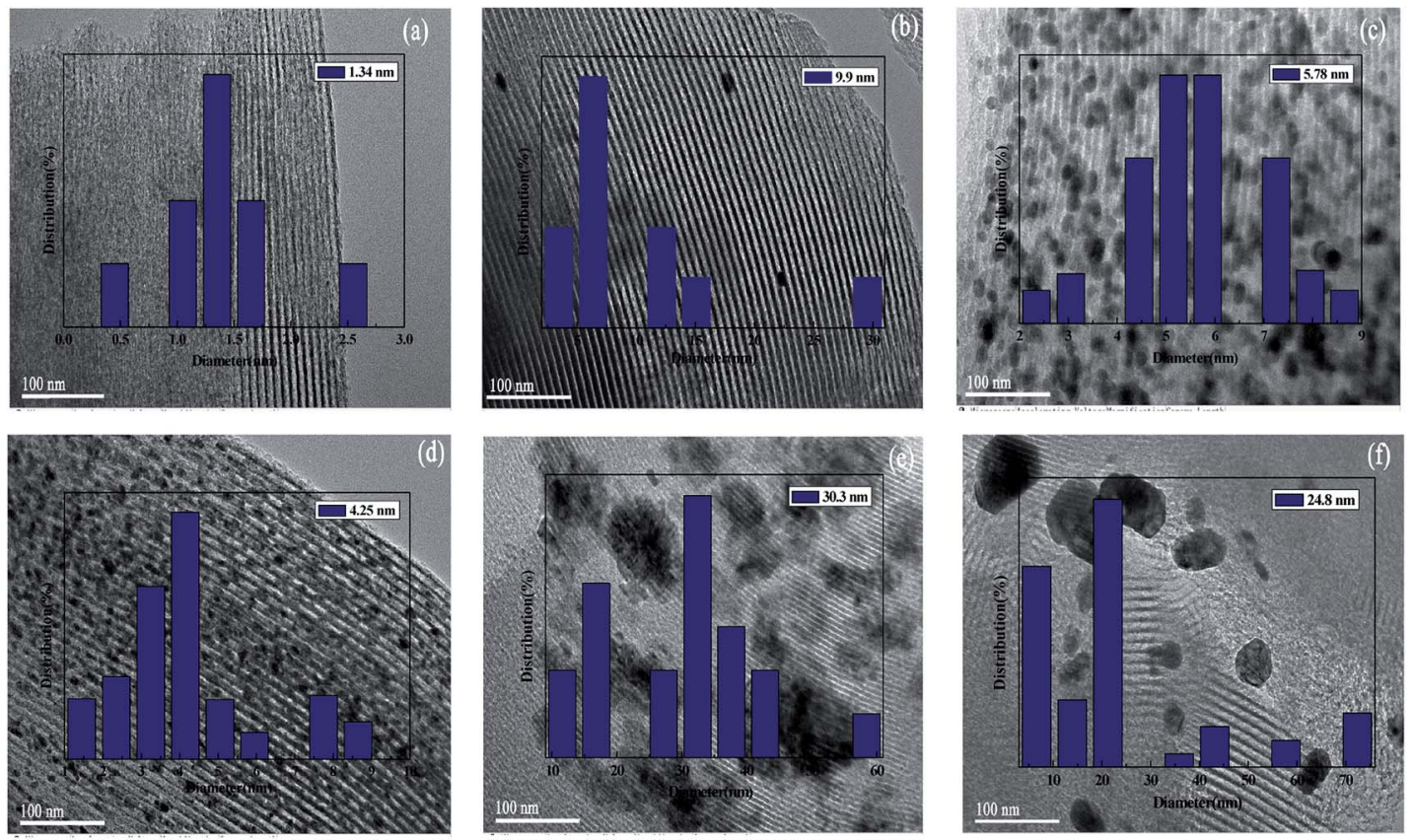

Fig. 3 TEM images of M/SBA-15 (scale bar, 100 nm): (a) Au/SBA-15; (b) Pt/SBA-15; (c) Rh/SBA-15; (d) Ru/SBA-15; (e) Ni/SBA-15; (f) Pd/SBA-15. 


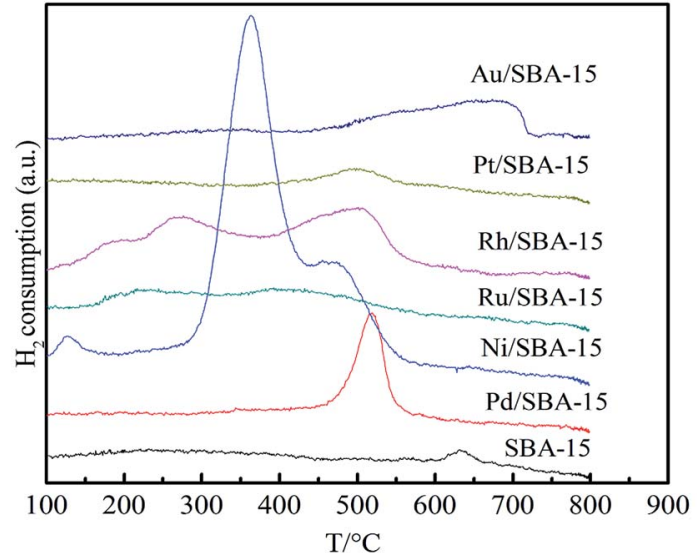

Fig. $4 \mathrm{H}_{2}$-TPR profiles of the SBA-15 and M/SBA-15 samples.

Table 2 The selectivity of the main polyols from the cellulose conversion over the different binary catalysts ${ }^{a}$

\begin{tabular}{lllllllll}
\hline & & \multicolumn{7}{c}{ Selectivity/\% } \\
\cline { 5 - 8 } Entry & Catalyst/g & Conversion/\% & EG & SO & MA & PG & GY \\
\hline 1 & TPA & 100 & 0 & 0 & 0 & 0 & 0 \\
2 & Ru/SBA-15 & 98 & 13.0 & 1.0 & 0 & 1.4 & 1.4 \\
3 & Pd/SBA-15 + TPA & 100 & 31.8 & 0 & 2.2 & 11.3 & 2.0 \\
4 & Ni/SBA-15 + TPA & 100 & 29.2 & 0 & 0.3 & 10.6 & 1.9 \\
5 & Ru/SBA-15 + TPA & 100 & 55.5 & 9.9 & 2.1 & 2.6 & 5.5 \\
6 & Rh/SBA-15 + TPA & 100 & 35.5 & 3.8 & 6.8 & 6.2 & 2.2 \\
7 & Pt/SBA-15 + TPA & 100 & 24.4 & 1.2 & 0.4 & 10.3 & 1.5 \\
8 & Au/SBA-15 + TPA & 100 & 11.0 & 0.5 & 0 & 12.6 & 0
\end{tabular}

${ }^{a}$ Reaction conditions: $0.5 \mathrm{~g}$ of cellulose; $0.1 \mathrm{~g}$ of catalyst; $0.02 \mathrm{~g}$ of $\mathrm{H}_{3} \mathrm{PW}_{12} \mathrm{O}_{40}$ (TPA); $25 \mathrm{~mL} \mathrm{H} \mathrm{H}_{2} \mathrm{O}$; reaction temperature, $245{ }^{\circ} \mathrm{C}$; reaction time, $4 \mathrm{~h} ; \mathrm{H}_{2}$ pressure, $5 \mathrm{MPa}$.

binary catalyst in the selective formation of EG from cellulose. From Table 2, it is observed that different combinations of the binary catalyst have a significant impact on the selectivity of EG. The best selectivity to EG (55\%) was observed when the binary catalyst of Ru/SBA-15 and TPA was used (Entry 5), whereas the worst selectivity to EG (11\%) was observed when using Au/SBA15 and TPA as the binary catalyst (Entry 8). Our results indicate that the binary catalyst of Ru/SBA-15 and TPA achieve higher EG selectivity than that obtained in a previous report. Ribeiro et al. reported that the EG yield reached the $34.8 \%$ using $\mathrm{Ru}-\mathrm{W} / \mathrm{CNT}$ as the catalyst. ${ }^{29}$ Moreover, the selectivity to EG for the catalysts such as Pd, Ni and Pt modified-SBA-15 were $31.8 \%, 29.2 \%$ and $24.4 \%$ (Entries 3-4 and 7), respectively, which is lower than that obtained for the other metal phase modified-SBA-15 catalysts such as Ru and Rh modified-SBA-15. Based on the above $\mathrm{N}_{2}$ adsorption-desorption analysis results, $\mathrm{Ru}(\mathrm{Rh})-\mathrm{SBA}-15$ catalyst has larger BET surface area and pore volume than the other metal phase modified-SBA-15, indicating that the hydrogenated molecules can more easily contact with hydrogenation active sites in the Ru (Rh)-SBA-15 catalyst. Moreover, the TEM images could provide additional clues for the EG selectivity from the dispersion of metal phase on the SBA-15 support. Ru and Rh metal particles were well dispersed on the surface of the SBA-15, but Ni, Pd and Pt-modified catalysts showed distinct dark zones on the TEM images due to the metal particles aggregation. As shown in Table 2, it was found that the order of EG selectivity for M/SBA-15 metal element catalyst was $\mathrm{Ru}>\mathrm{Rh}>\mathrm{Ni}>\mathrm{Pd}>\mathrm{Ni}>$ Pt $>$ Au.

\subsection{Effects of combination of $\mathrm{M} / \mathrm{SBA}-15$ with various $W$ species on the selectivity of polyols and EG product}

Fig. 5 shows the effect of different binary catalysts on the selectivity of the polyols, EG and the distribution of the polyol products. According to Fig. 5(a), it was found that different $\mathrm{W}$ compounds, namely, $\mathrm{H}_{2} \mathrm{WO}_{4}$ (TA), $\mathrm{H}_{3} \mathrm{PW}_{12} \mathrm{O}_{40}$ (TPA) and $\mathrm{H}_{4} \mathrm{SiW}_{12} \mathrm{O}_{40}$ (TSA) have an important impact on the selectivity of polyols. For example, when using TA, TPA and TSA in combination with Pt/SBA-15 as binary catalysts, the polyols selectivity were $35.9 \%, 47.3 \%$ and $65.2 \%$, respectively. The results suggest that $\mathrm{W}$ compounds play a key role in the selective formation of polyols from cellulose. This can be explained by the fact that the $\mathrm{W}$ compounds with acid sites can promote the hydrolysis

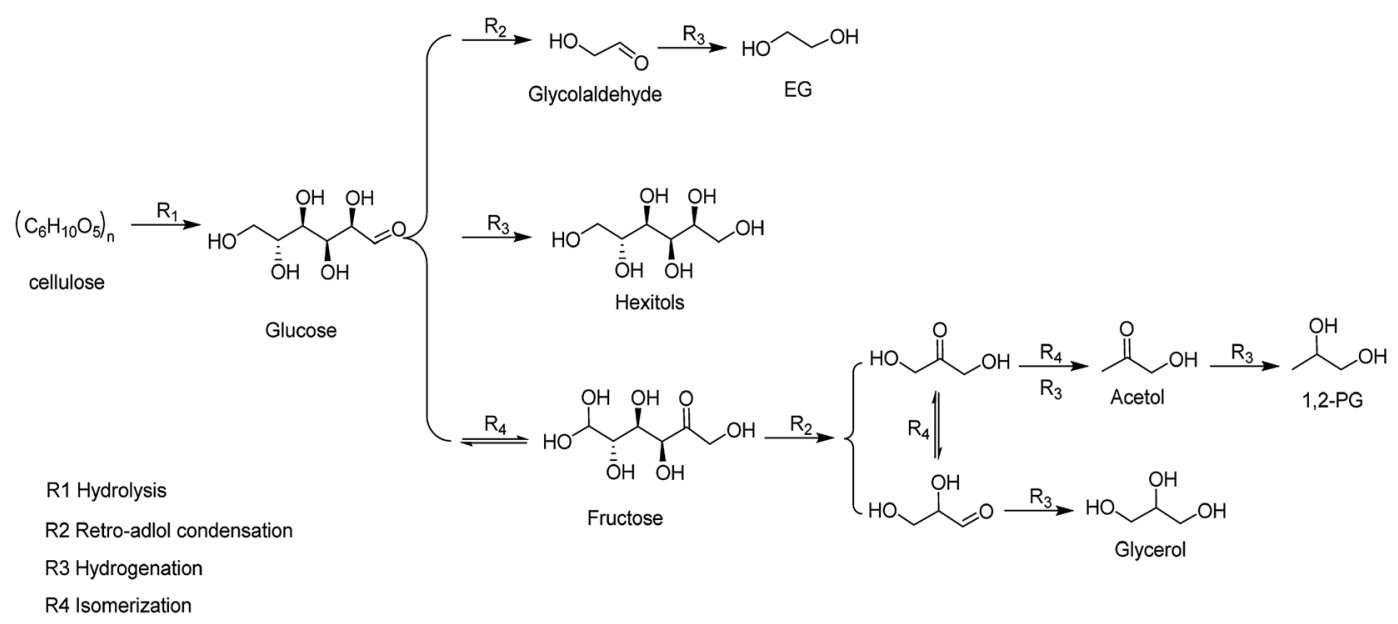

Scheme 1 Catalytic conversion for cellulose into polyols. 

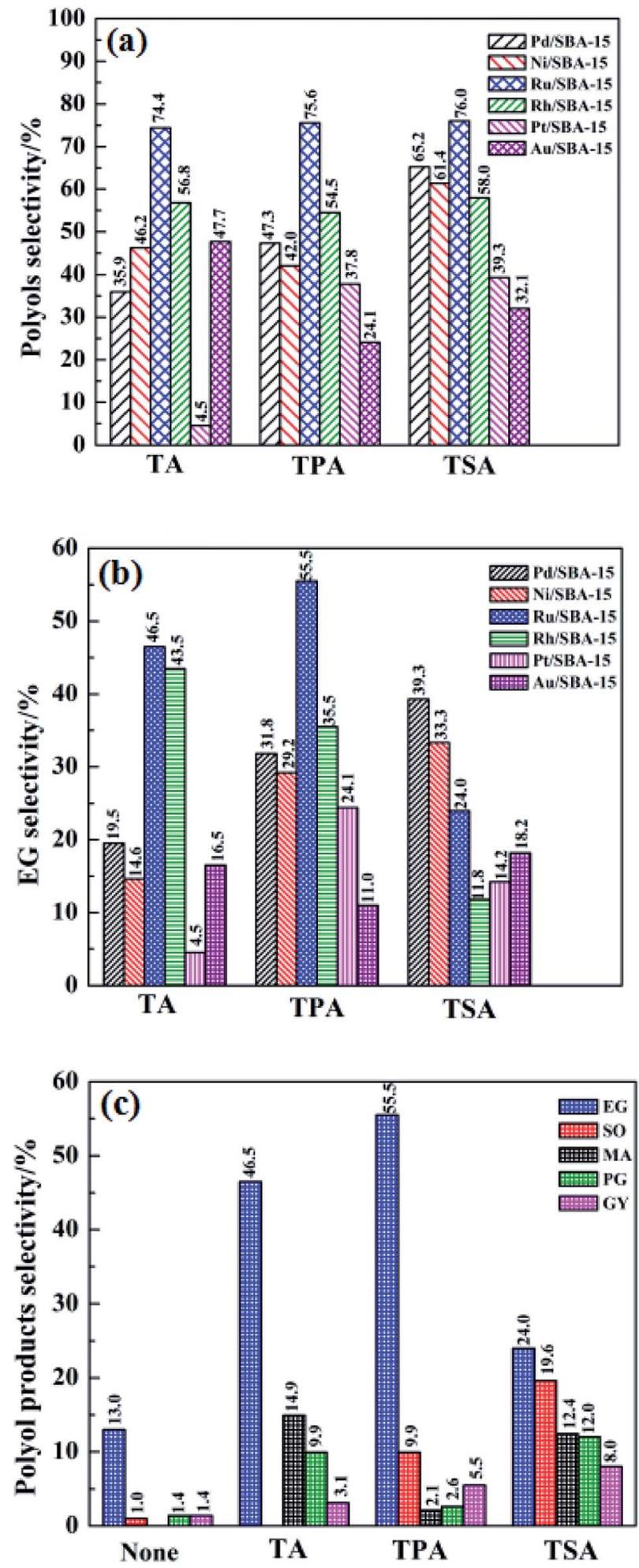

Fig. 5 The selectivity of the polyols and EG as well as the main products for the catalytic conversion cellulose ((a): polyols selectivity; (b): EG selectivity; (c): product selectivity). Reaction conditions: $0.5 \mathrm{~g}$ of cellulose; $0.1 \mathrm{~g}$ of M/SBA-15; $0.02 \mathrm{~g}$ of $\mathrm{W}$ compound; $25 \mathrm{~mL} \mathrm{H} \mathrm{H}_{2} \mathrm{O}$; reaction temperature, $245^{\circ} \mathrm{C}$; reaction time, $4 \mathrm{~h} ; \mathrm{H}_{2}$ pressure, $5 \mathrm{MPa}$.

and $\mathrm{C}-\mathrm{C}$ breaking reactions of cellulose. Interestingly, regardless of the type of $\mathrm{W}$ compounds used, the polyols selectivity is always high in the presence of Ru/SBA-15 catalyst, indicating that $\mathrm{Ru} / \mathrm{SBA}-15$ exhibit excellent catalytic performance in the selective formation of polyols. This may be due to the fact that $\mathrm{Ru}$ particles are well dispersed on the SBA-15 support to form more hydrogenation active sites (seeing Fig. 3(d)).

The effect of different binary catalysts on the EG selectivity was investigated, and the detailed results are shown in Fig. 5(b). It was found that the binary catalyst of Ru/SBA-15 and TPA gave the highest EG selectivity (55.5\%), whereas the EG selectivity of $46.5 \%$ and $24.0 \%$ were obtained when the Ru/SBA- 15 was combined with TA and TSA, respectively. This indicates that the combination of Ru/SBA- 15 and TPA show better synergy in the selective formation of EG from cellulose than other binary catalysts. In order to further shed light on the potential of the $\mathrm{Ru} / \mathrm{SBA}-15$ catalyst in the catalytic conversion of cellulose, the effect of binary catalyst of $\mathrm{Ru} / \mathrm{SBA}-15$ and different $\mathrm{W}$ compounds on the distribution of polyol products was investigated. As shown in Fig. 5(c), the addition of W compounds can effectively improve the polyol products selectivity, particularly the EG selectivity, which increases from $13.0 \%$ to $55.5 \%$ after the addition of TPA. At the same time, it can be seen that regardless of which $\mathrm{W}$ compound was used in combination with $\mathrm{Ru} / \mathrm{SBA}-15$, EG was always predominant product. These results indicate that $\mathrm{W}$ compounds play an important role in the selective formation of EG from cellulose. It is worth noting that the lower EG selectivity (24.0\%) and higher SO selectivity (19.6\%) were observed when using TSA and Ru/SBA-15 as the binary catalyst. The reason for higher SO selectivity and lower EG selectivity can be explained as follows: TSA catalyze the cleavage of $\mathrm{C}-\mathrm{C}$ bonds of cellulose by retro-aldol reaction, but it is less active to $\mathrm{C}-\mathrm{C}$ breaking reaction of cellulose so that it results in lower EG selectivity. ${ }^{13}$ Based on the above analysis, we can conclude that the EG selectivity depended on the $\mathrm{W}$ compounds in the presence of the Ru/SBA-15 in the following order: TSA $<$ TA $<$ TPA. These results show the potential of the binary catalyst of $\mathrm{Ru} / \mathrm{SBA}-15$ and TPA in the selective formation of EG from cellulose. As Ru/SBA-15 and TPA system has good selectivity to EG, the binary catalyst was chosen for the further study.

\subsection{The effect of reaction conditions on the distribution of main products}

In order to improve the EG selectivity, the reaction conditions for the catalytic conversion of cellulose using the binary catalyst of Ru/SBA- 15 and TPA as catalyst were investigated. Fig. 6 shows the effect of catalyst dosage on the distribution of polyol products. Fig. 6(a) displays the effect of the Ru/SBA-15 dosage on the distribution of polyol products. As shown in Fig. 6(a), the selectivity of EG increased with the increase in the Ru/SBA-15 dosage from $0.0 \mathrm{~g}$ to $0.1 \mathrm{~g}$. When the catalyst $\mathrm{Ru} / \mathrm{SBA}-15$ dosage was $0.1 \mathrm{~g}$, EG selectivity reached the maximum of $55.5 \%$. However, when the Ru/SBA-15 dosage was $0.14 \mathrm{~g}$, the selectivity of EG decreased to $49.3 \%$. This can be explained by the fact that the more the amount of Ru/SBA-15, the faster would be the reaction for EG hydrogenolysis. ${ }^{11}$ Therefore, the optimal the amount of Ru/SBA- 15 seems to be 0.1 g. Fig. 6(b) shows the effect of the TPA dosage on the distribution of polyol 

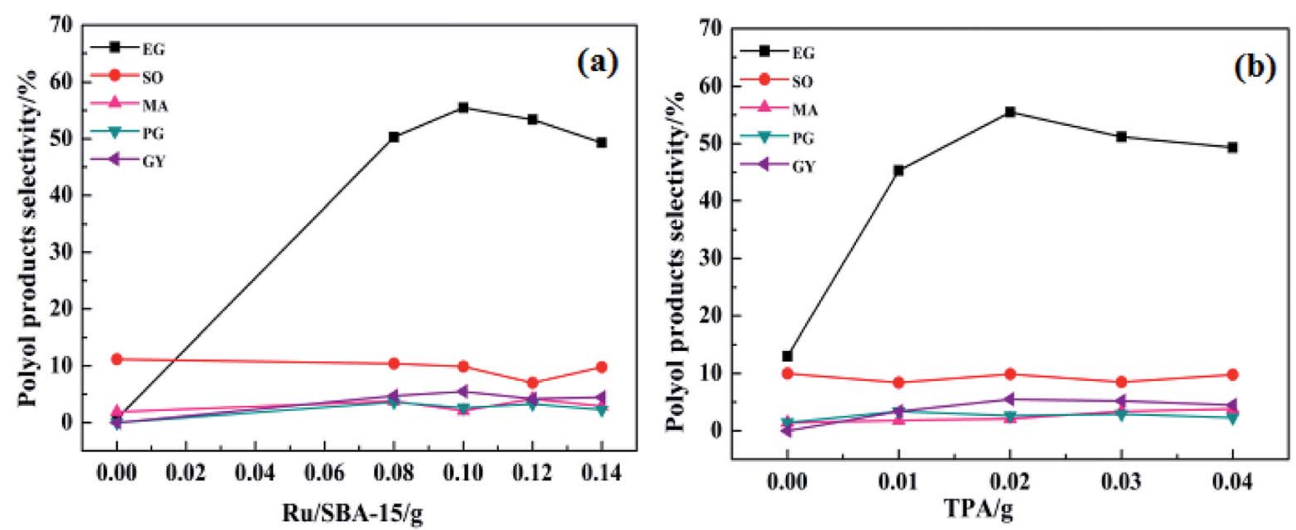

Fig. 6 The effect of catalyst dosage on the selectivity of the main products (a) $0.5 \mathrm{~g}$ of cellulose; $0.02 \mathrm{~g}$ of TPA; $25 \mathrm{~mL} \mathrm{H}_{2} \mathrm{O}$; reaction temperature, $245^{\circ} \mathrm{C}$; reaction time, $4 \mathrm{~h} ; \mathrm{H}_{2}$ pressure, $5 \mathrm{MPa}$. (b) $0.1 \mathrm{~g}$ of Ru/SBA-15 and the other reaction conditions were the same as (a) above mentioned.
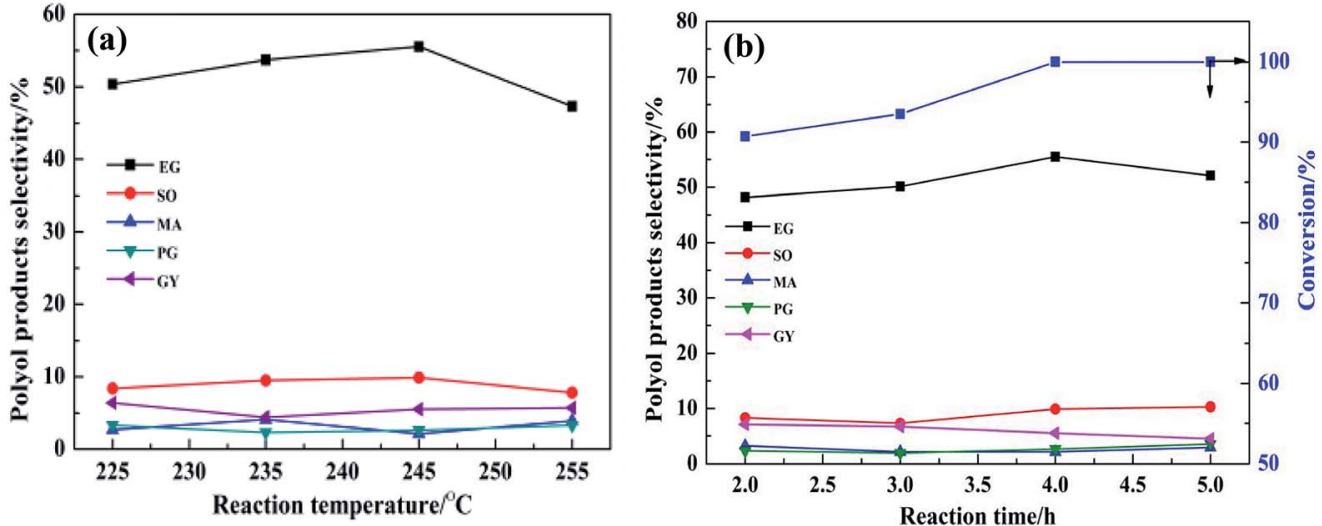

Fig. 7 The effect of reaction temperature and time on the selectivity of the main products (a) $0.5 \mathrm{~g}$ of cellulose; $0.1 \mathrm{~g}$ of Ru/SBA-15; $0.02 \mathrm{~g}$ of TPA; $25 \mathrm{~mL} \mathrm{H} \mathrm{H}_{2} \mathrm{O}$; reaction temperature, $245^{\circ} \mathrm{C} ; \mathrm{H}_{2}$ pressure, $5 \mathrm{MPa}$. (b) Reaction time, $4 \mathrm{~h}$, and the other reaction conditions were the same as (a).

products. According to Fig. 6(b), when only Ru/SBA-15 was used, the polyol products such as EG, SO and MA were produced from the $\mathrm{C}-\mathrm{C}$ breaking reaction of cellulose. This indicates that $\mathrm{Ru}-$ SBA-15 not only possesses hydrogenation properties, but also has hydrogenolysis ability. Compared with no TPA, the addition of TPA can greatly improve the EG selectivity. For example, when the amount of TPA was $0.02 \mathrm{~g}$ and on fixing the amount of $\mathrm{Ru} / \mathrm{SBA}-15$ at $0.1 \mathrm{~g}$, EG selectivity was enhanced from $13.0 \%$ to $55.5 \%$. Nevertheless, when the TPA dosage was $0.03 \mathrm{~g}$, the EG selectivity decreased to $51.2 \%$. Similar to the influence of the $\mathrm{Ru} / \mathrm{SBA}-15$ content, the selectivity for EG also showed a volcano curve with the change in the amount of TPA, signifying that a good balance between $\mathrm{Ru} / \mathrm{SBA}-15$ and TPA is required. Based on the above results, the binary catalyst combination of $0.1 \mathrm{~g}$ $\mathrm{Ru} / \mathrm{SBA}-15$ and $0.02 \mathrm{~g}$ TPA shows the best catalytic performance for EG selectivity from catalytic conversion cellulose.

The plot showing the effect of reaction temperature on the distribution of polyol products is displayed in Fig. 7(a). As the reaction temperature increased from $225{ }^{\circ} \mathrm{C}$ to $245{ }^{\circ} \mathrm{C}$, the EG selectivity increased from $50.4 \%$ to $55.5 \%$, respectively. This might be due to the fact that more $\mathrm{H}^{+}$was produced from hot compressed water at higher temperature to promote the conversion of cellulose, and/or the higher temperature might provide more energy for the cleavage of $\mathrm{C}-\mathrm{C}$ bond of sugar intermediates..$^{30}$ When the temperature was increased to $255^{\circ} \mathrm{C}$, the selectivity for EG decreased to $47.3 \%$. This may be due to the deactivation of active sites or the degradation of EG product at higher temperature. Therefore, the optimum operating temperature was set as $245^{\circ} \mathrm{C}$. Fig. 7 (b) displays the effect of reaction time on the distribution of polyol products. When the reaction time was increased from $2.0 \mathrm{~h}$ to $4.0 \mathrm{~h}$, the EG selectivity increased from $48.2 \%$ to $55.5 \%$, respectively. With prolonged reaction time, the selectivity to EG decreased from $55.5 \%$ to $52.1 \%$. This is ascribed to the long reaction time favoring side reactions such as hydrogenolysis of EG. ${ }^{11}$ Therefore, the optimum reaction conditions for EG selectivity were as follows: Ru/SBA-15: $0.1 \mathrm{~g}$; TPA: $0.02 \mathrm{~g} ; 245{ }^{\circ} \mathrm{C}, 4 \mathrm{~h}$. Under the abovementioned conditions, the EG selectivity reached nearly $55.5 \%$.

\section{Conclusion}

The direct catalytic conversion of cellulose into EG was investigated over the various binary catalysts composed of M/SBA-15 and $\mathrm{W}$ compounds. A remarkable advantage of these binary catalysts was that it not only led to a nearly $100 \%$ conversion of 
cellulose, but also gave the higher selectivity for EG. Among the binary catalysts, Ru/SBA-15 and TPA system showed the excellent performance for EG selectivity (about 55.5\%). More importantly, compared with single catalyst, the use of the binary catalyst can significantly improve the EG selectivity due to the synergistic effect between M/SBA-15 and W compounds. Moreover, the SBA-15 mesoporous material, which has a large surface area and ordered hexagonal mesopore, facilitates not only the high dispersion of metal element but also the transport of reactant and product molecules. Taking into account that the raw material used is cellulose and the importance of EG in the petrochemical industry, the new binary catalyst of Ru/SBA-15 and TPA is a promising candidate for the production of EG from cellulose in the future.

\section{Conflicts of interest}

There are no conflicts to declare.

\section{Acknowledgements}

This study was financially supported by the Natural Science Foundation of China (31370570 and 31100430), the Taishan Scholars Projects of Shandong (ts201511033), the Key R\&D Project of Shandong (2017GGX40106), and the People's Livelihood Science and Technology Project of Qingdao (173383NSH). The authors are also grateful for the experimental conditions which the Polyphase Fluid Reaction and Separation Engineering Key Laboratory of the Shandong give.

\section{References}

1 M. A. Harmer, A. Fan, A. Liauw and R. K. Kumar, A new route to high yield sugars from biomass: phosphoric-sulfuric acid, Chem. Commun., 2009, 6610-6614.

2 D. L. Klass, Biomass for renewable energy, fuels, and chemicals, 1998, 29, 1028-1037.

3 J. Pang, A. Wang, M. Zheng, Y. Zhang, Y. Huang and X. Chen, Catalytic conversion of cellulose to hexitols with mesoporous carbon supported Ni-based bimetallic catalysts, Green Chem., 2012, 14, 614-617.

$4 \mathrm{Y}$. Yu, L. Xia and H. Wu, Some recent advances in hydrolysis of biomass in hot-compressed water and its comparisons with other hydrolysis methods, Energy Fuels, 2008, 22, 46-60.

5 A. Fukuoka and P. L. Dhepe, Catalytic conversion of cellulose into sugar alcohols, Angew. Chem., 2006, 45, 5285-5287.

6 V. Stijn, G. Jan, P. A. Jacops and B. F. Sels, Recent advances in the catalytic conversion of cellulose, ChemCatChem, 2011, 3, 82-94.

7 J. Geboers, D. V. S. Van, K. Carpentier, P. Jacobs and B. Sels, Efficient hydrolytic hydrogenation of cellulose in the presence of Ru-loaded zeolites and trace amounts of mineral acid, Chem. Commun., 2011, 47, 5590-5592.

8 D. V. S. Van, J. Geboers, M. Dusselier, H. Schepers, T. Vosch and L. Zhang, Selective bifunctional catalytic conversion of cellulose over reshaped $\mathrm{Ni}$ particles at the tip of carbon nanofibers, Chemsuschem, 2010, 3, 698-701.
9 J. N. Chheda, G. W. Huber and J. A. Dumesic, Liquid-Phase catalytic processing of biomass-derived oxygenated hydrocarbons to fuels and chemicals, Angew. Chem., Int. Ed., 2007, 46, 7164-7183.

$10 \mathrm{H}$. Yue, Y. Zhao, X. Ma and J. Gong, Ethylene Glycol: Properties, Synthesis, and Applications, Chem. Soc. Rev., 2012, 41, 4218-4424.

11 Z. Tai, J. Zhang, A. Wang, J. Pang, M. Zheng and T. Zhang, Catalytic conversion of cellulose to ethylene glycol over a low-cost binary catalyst of Raney $\mathrm{Ni}$ and tungstic acid, Chemsuschem, 2013, 6, 652-658.

12 C. Luo, S. Wang and H. Liu, Cellulose conversion into polyols catalyzed by reversibly formed acids and supported ruthenium clusters in hot water, Angew. Chem., 2007, 119, 7780-7783.

13 Z. Tai, J. Zhang, A. Wang, M. Zheng and T. Zhang, Temperature-controlled phase-transfer catalysis for ethylene glycol production from cellulose, Chem. Commun., 2012, 48, 7052-7054.

14 N. Ji, T. Zhang, M. Zheng, A. Wang, H. Wang, X. Wang and J. G. Chen, Direct Catalytic conversion of cellulose into ethylene glycol using nickel-promoted tungsten carbide catalysts, Angew. Chem., Int. Ed., 2008, 47, 8510-8513.

15 Y. Zhang, A. Wang and T. Zhang, A new 3D mesoporous carbon replicated from commercial silica as a catalyst support for direct conversion of cellulose into ethylene glycol, Chem. Commun., 2010, 46, 862-864.

16 M. Y. Zheng, A. Q. Wang, N. F. Pang, X. D. Wang and T. Zhang, Transition metal-tungsten bimetallic catalysts for the conversion of cellulose into ethylene glycol, ChemSusChem, 2010, 3, 63-66.

17 Y. L. Cao, J. W. Wang, L. I. Q. Feng, N. Yin, Z. M. Liu, M. Q. Kang and Y. L. Zhu, Hydrolytic hydrogenation of

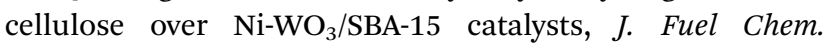
Technol., 2013, 41, 943-949.

18 M. Baca, E. D. L. Rochefoucauld, E. Ambroise, J. M. Krafft, R. Hajjar, P. P. Man, X. Carrier and J. Blanchard, Characterization of mesoporous alumina prepared by surface alumination of SBA-15, Microporous Mesoporous Mater., 2008, 110, 232-241.

19 Y. Zheng, F. Wang, X. Yang, Y. Huang, C. Liu and Z. Zheng, Study on aromatics production via the catalytic pyrolysis vapor upgrading of biomass using metal-loaded modified H-ZSM-5, J. Anal. Appl. Pyrolysis, 2017, 126, 169-179.

20 X. Zhang, Q. Zhang, T. Wang, B. Li, Y. Xu and L. Ma, Efficient upgrading process for production of low quality fuel from bio-oil, Fuel, 2016, 179, 312-321.

21 G. E. Luz Jr, A. G. D. Santos, A. C. R. Melo, R. M. Oliveira, A. S. Araujo and V. J. Fernandes Jr, Thermal catalytic cracking of buriti oil over LaSBA-15 mesoporous materials, Fuel Process. Technol., 2011, 92, 2099-2104.

22 Y. S. Ooi and S. Bhatia, Aluminum-containing SBA-15 as cracking catalyst for the production of biofuel from waste used palm oil, Microporous Mesoporous Mater., 2007, 102, 310-317.

23 M. C. G. Albuquerque, I. Jimenez-Urbistondo, J. SantamariaGonzalez, J. M. Merida-Robles, R. Moreno-Tost, 
E. Rodrrguez-Castellon, A. Jimenez-Lopez, D. C. S. Azevedo, C. L. Cavalcante Jr and P. Maireles-Torres, CaO supported on mesoporous silicas as basic catalysts for transesterification reactions, Appl. Catal., A, 2008, 334, 3543.

24 Y. L. Wei, Y. Cao and J. H. Zhu, Attempts on preparing mesoporous basic material MgO/SBA-15, Stud. Surf. Sci. Catal., 2004, 154, 878-885.

25 D. Zhao, J. Feng, Q. Huo, N. Melosh, G. H. Fredrickson, B. F. Chmelka and G. D. Stucky, Triblock copolymer syntheses of mesoporous silica with periodic 50 to 300 angstrom pores, Science, 1998, 279, 548-552.

26 S. Y. Wang, W. Z. He, C. Liu, G. M. Li and F. E. Zhang, Characterizations and preparation of $\mathrm{Mg}(\mathrm{OH})_{2}$ nanocrystals through ultrasonic-hydrothermal route, Res. Chem. Intermed., 2016, 42, 4135-4145.
27 V. Jollet, F. Chambon, F. Rataboul, A. Cabiac, C. Pinel, E. Guillon and N. Essayem, Tungsten trioxide promoted selective conversion of cellulose into propylene glycol and ethylene glycol on a ruthenium catalyst, Angew. Chem., 2012, 13, 3303-3307.

28 M. Y. Zheng, J. F. Pang, R. Y. Sun, A. Wang and T. Zhang, Selectivity control for cellulose to diols: dancing on eggs, ACS Catal., 2017, 7, 1939-1954.

29 L. S. Ribeiro, J. Órfão, J. J. D. M. Órfão and M. F. R. Pereira, Hydrolytic hydrogenation of cellulose to ethylene glycol over carbon nanotubes supported $\mathrm{Ru}-\mathrm{W}$ bimetallic catalysts, Cellulose, 2018, 25, 2259-2272.

30 V. Jollet, F. Chambon, F. Rataboul, A. Cabiac, C. Pinel, E. Guillon and N. Essayem, Non-Catalyzed and $\mathrm{Pt} / \gamma-\mathrm{Al}_{2} \mathrm{O}_{3}$ catalyzed hydrothermal cellulose dissolution-conversion: influence of the reaction parameters, Top. Catal., 2010, 53, 1254-1257. 